\title{
PARA UNA CARACTERIZACIÓN EPISTÉMICA Y METODOLOGICA DE LAS CIENCIAS SOCIALES
}

\author{
Francesc Quintana
}

\section{Resumen}

Constatar el vacio que deja lo que ba sido categorizado como caducidad de los "grandes relatos", constituye el punto de partida o premisa de este texto; lo cual tiene su plasmación en el ámbito de las ciencias sociales, afectando a las dos grandes corrientes que han prevalecido a lo largo de más de sesenta años, esto es: marxismo y funcionalismo. La inexistencia de marcos téricos consistentes capaces de dar cuenta y aprehender (sinónimo de captura y depredación) los fenómenos que acontecen en las formaciones capitalistas de fin de siglo, mezcla compleja, cabtica de "neofordismo" $y$ "postfordismo" aparece como la consecuencia más inmediata. Lo que pone de manifiesto la importancia básica de indagar y definir acerca del "lugar de la enunciación". Los elementos que se proponen aqui, a modo de conjetura, desde una bptica afin al "desconstrucciontsmo", muestran el carácter en tanto que producción discursiva y autorreferencial de estos saberes, en los que destacan "umbrales" y "reglas" que operan en su despliegue retórico. Discursos y reglas vehiculados por especificos artefactos cientifico-tecnicos para la inteligibilidad de lo social informatizado. Tales saberes $y$ artefactos tecnológicos (recurrentes, sociobistbricos y portadores de una insoslayable dimension politica y formalizadora) topan en su funcionalidad codificadora y de regulación con un límite, a saber: La naturaleza básicamente impredectible, estocástica, del "magma social En cualquier caso, esta situación y, más en concreto, sus repercusiones en los artefactos cientifico-técnicos, tiene efectos paradojicos. Por un lado es sintomática de la vulnerabilidad de los instrumentos de análisis e intervención "normalizadora". Pero, por otro, abre un abanico de posibilidades en un sentido profundamente critico y desconstructivo, que permite jugar con el carácter uintensional" del pensamiento. Ello supone gue las descripciones o aseveraciones pueden "flotar" sin estar necesariamente adheridas a objeto conocido alguno.

Resum

Constatar el buit que deixa el que ha estat categoritzat com a caducitat dels "grans relatts" constitueix el punt de partida o premissa d'aquest text. Aixó té la seva plasmació en l'ambit de les ciències socials, i afecta els dos grans corrents que han prevalgut al llarg de més de seixanta anys, és a dir: marxisme i funcionalisme. La inexistència de marcs teòrics consistents, capacos de donar compte i d'aprehendre (sinònim de captura i depredació) els fenòmens que esdevenen 
en les formacions capitalistes de finalas de segle, barreja complexa, caòtica de "neofordisme" $i$ "postfordisme", apareix com la consequïncia més immediata $i$ posa de manifest, sobretot, la importancia basica d'indagar $i$ definir el clloc de lenunciación. Els elements que es proposen aci, a manera de conjectura, des d'una optica afi al "desconstruccionisme", mostren el caràcter com a producció discursiva $i$ autoreferencial d'aquests sabers, en els quals destaquen "llindars" $i$ "regles" que operen el seu desplegament retòric. Discursos i regles vehiculats per especifics artefactes cientifico-tecnics per a la intel ligibilitat del fet social informatitzat. Aquests sabers i artefactes tecnologics (recurrents, sociohistòrics i portadors d'una ineludible dimensio politica if formalitzadora) topen, en la seva funcionalitat codificadora i de regulacib, amb un limit, a saber: La natura basicament impredictible, estocàstica, del "magma social". De qualsevol manera, aquesta situació i, mès en concret, les seves repercussions en els artefactes cientifico-tècnics, te efectes paradoxals. Per una banda és simtomàtic de la vulnerabilitat dels instruments d'analissi $i$ d'intervenció "normalitzadora". Però, per altra banda, obre un ventall de possibilitats en un sentit profundament critic $i$ desconstructiu que permet jugar amb el caràcter «intensionals del pensament. Això suposa que les descripcions o asseveracions poden aflotar" sense estar necessàriament adherides a algun objecte conegut.

Abstract

To confirm the gap left by what has been classified as lapse of the "great reports" is the starting point of this text. Which takes shape within the boundaries of the social sciences, affecting the two main tendencies which have prevailed for more than fifty years, that is: marxism and functionalism. The non-existence of firm theoretical frames, able to account for and understand (a synonim of capture and depredation) the phenomena that occur in the capitalist formations of the end of the century, a complex, chaotic mixture of "neofordism" and "postfordism" emerges as the most immediate consequence, and reveals, above all, defining and delving into the "place of the statement". The elements proposed bere, in a way of guess, from a vieupoint similar to that of the "desconstruccionism" show their character as discoursive and self-referential production of this knowledge, from which "thresholds" and "rules" outstand and operate in their rethorical display. Discourses and rules conveyed by specific scientific-technical devices for the intelligibility of the social computerized. Such knowledge and technological devices (recurrent, sociohistorical and conveyers of an unavoidable political dimension) come up against a boundary in their codifying functional character, namely: the basically impredicatable, stocastic nature of the "social magma". Anyway, this situation and, more specifically, its repercussions on the aforementioned technological devices, has paradoxical effects. On the one hand, it is symptomatic of the vulnerability of the instruments of analysis and a "normalizer" intervention. But, on the other hand it spreads out a whole range of possibilities in a deeply critical and desconstructive sense, which allows to play with the "intensional" character of thought. That supposes that the descriptions or claims can "float" without being necessarily stuck to any known object whatsoever. 
Para una caracterización espistémica y metodológica de las Ciencias Sociales

\section{LA PREMISA}

La pregunta por el pensar y por la acción, entendida en un sentido genérico, suscita, a su vez o implícitamente, una cuestión neurálgica, a saber: la de la unilateralidad. Dicho de otro modo, desde que lugar y de que manera discurre la actividad reflexiva y práctica en este ámbito.

Sobre este particular, el texto que se propone, a modo de ensayo, pretende ser una aportación al debate acerca de la caracterización del alugar de la enunciación" y de la naturaleza de las ciencias sociales. A ello habría que añadir algo que constituye aquí una premisa, esto es, el reconocimiento del relativo vacío que invade este dominio de la investigación, y que se traduce en la ausencia de referentes o de marcos teóricos consistentes.

Por otra parte, y sin que de ello haya que extraer conclusiones apresuradas o simplemente falsas - al amparo del revival neoliberal en sus versiones neolockeana o al estilo de Lypovetsky - algo que se percibe cada vez con mayor claridad, es la inadecuación de las lecturas "clásicas" (lo cual no deja de tener sus ventajas para los textos o registros materiales objeto de indagación, desde el punto de vista crítico que considera la funcionalidad sistérnica de aquella cientificidad y de aquellas prácricas), de los modelos teóricos y dispositivos tecnológicos al uso para dar cuenta concretamente de los fenómenos que acontecen en las formaciones del capitalismo inregrado: mezcla compleja y asistemática en el orden productivo social de "neofordismo" y "postfordismo". $\mathrm{O}$, de acuerdo con la terminología kuhneana, de la inexistencia de paradigma dentro del cual desarroliar esa actividad depredadora, consistente en dilucidar los enrtesijos de lo social, en descubrir núcleos de inteligibilidad, ejemplifica perfectamente esta situación. Si bien, en este caso, se tratarfa tan sólo de una constatación, y no de buscar un apoyo sólido en que fundar nuestras certidumbres.

Aunque ésra es una temática sobre la que siempre puede y debe volverse, por el momento nos limitaremos a cirar un par de casos ilustrativos de las profundas divergencias existentes al respecto. Así, J. C. Alexander (1990) se ha referido a la "centralidad" y relevancia de los "clásicos" (Marx, Durkheim, Weber...), donde se destaca de un modo particular la relectura de Parsons. La postura de F. J. Lyotard (1979) es, sin embargo, muy otra, al poner de manifiesto, como una característica de la contemporaneidad, el declive experimentado por las dos grandes corrientes que han marcado el desarrollo de las ciencias sociales a lo largo de más de medio siglo: marxismo (hegelomarxismo frankfurtiano, marxismo estructuralista, neomarxismo,...) y funcionalismo (weberiano, parsoniano, sistémicos,...). Corrientes éstas que han diseñado sus respectivos modelos de sociedad. Según la concepción marxista, al entender la estructura social como dualidad internamente contradictoria, que logra finalmente su unidad por la intervención en esa realidad dialéctica de las luchas 
de clases. Para los funcionalistas, y en particular para Talcott Parsons (1951), la estructura social es descrita como una totalidad funcional.

Desde una perspectiva más amplia, poniendo el acento en los elementos gnoseológicos e historiográficos, diversos autores han dedicado su atención al tema de la crisis y obsolescencia de aquellas corrientes y, más concretamente, al de los enfoques positivistas, neopositivistas y racionalistas críticos. Cabe citar, a este respecto, a P. K. Feyerabend $(1975,1981)$, T. Kuhn $(1981,1989)$, N. R. Hanson (1977), S. Toulmin (1970) y A. F. Chalmers (1986). El denominador común de estos autores, con planteamientos distintos, estriba en poner en tela de juicio las distintas modalidades de empirismo. En el área más especifica de las ciencias sociales, destacan las aportaciones de la "ontología foucaultiana" $(1978,1979)$, C. Castoriadis (1973, 1978), A. Guiddens (1987) y A. Gouldner (1979), con importantes repercusiones en producciones teóricas relevantes, como es el caso de la etnometodología (H. Garfinkel), la teoría del intercambio social (G. C. Homans) y la dramaturgia (E. Goffman).

\section{RETORICA CIENTIFICA Y DISCURSIVIDAD}

Como trasfondo de aquella episteme, que incluye una variada gama de empirismos, destacan grosso modo varias presuposiciones:

a) Dar por sentado que toda realidad natural/social posee un núcleo de verdad que hay que desvelar.

b) Esta verdad aparece objetivada en la realidad empírica, que es la que fundamenta la elaboración de los "sense data".

c) La captura de esa verdad se lleva a cabo con procedimientos de carácter metódico.

d) Existe una correspondencia entre los enunciados y descripciones etiquetados como científicos y los fenómenos ocurridos en la supuesta realidad (naturaleza, sociedad), estableciéndose entre ambos un vínculo mediador o de representación.

Dado su interés, podriamos añadir un par de características, a las que ha hecho referencia K. Gergen (1989), y que apuntan al lenguaje.

e) Participar de la creencia secular consistente en afirmar que la lengua es el principal instrumento a través del cual los humanos se representan el mundo.

f) En estrecha relación con lo anterior, se considera que la lengua es el vehículo par excellence para la comunicación de los contenidos mentales. 
Resulta indispensable puntualizar, a pesar de todo, que, contrariamente a la visión restrictiva de Gergen, circunscrita al lenguaje, bajo la aparente calma superficial de la lengua y del habla, se percibe la agitación y la refriega, producto del choque de artefactos y fuerzas, que pone de relieve la sustancia agonal de las prácticas, de las producciones discursivas y de los saberes explicitados en los juegos de lenguaje. Por consiguiente, podemos hablar de juegos de lenguaje, pero, eso sí, juegos que remiten finalmente a las formas de la disuasión y a la guerra como realidad fáctica y/o simulacro (Baudrillard, 1984, 1991).

Ahora bien, algo que no carece de interés en los comentarios de Gergen, $y$ que va a permitir introducir el punto de vista que aquí se esboza, es la alusión a la forma retórica del lenguaje científico. Lo cual significa afirmar que aquelio que da lugar a que determinada explicación o descripción puede ser considerada "objetiva", depende del cumplimiento de ciertas pautas, que rigen el uso de la retórica y, por tanto, que lo que finalmente otorga carácter de objetividad a una expresión, no es la presunta correspondencia entre "palabra" y uobjeto" - tal y como postulan los empiristas en general - sino la capacidad y el dominio de cierta habilidad retórica dependiente de reglas y criterios muy formalizados. De lo contrario, es decir, si se aceptara la existencia de esa correspondencia como algo consustancial y no arbitrario, ello nos sumiría en un proceso de recurrencia infinita para la consecución de una metateoría (Gödel), o de un metalenguaje (Derrida), que sirviera como fundamento último de esa presunta correspondecia entre esos supuestos, denominados, respectivamente, objeto y palabra. En última instancia, la controversia acerca de si el lenguaje o, en el caso que nos ocupa, el lenguaje especializado de las ciencias sociales, constituye una copia de una realidad preexistente, recnvía a alguna forma de pensamiento ingenuo. O bien, a la falacia del "representacionismo", reminiscencia platónica o neoplatónica desvelada de forma contundente por Deletuze en "Différence et répétition".

En definitiva, desde el punto de vista o "lugar" que aquí se propone, las descripciones y juegos de lenguaje que referencian objetos, acontecimientos,... conforman enunciados, discursos o formaciones discursivas, gestados en el marco de específicas formas de dominación. Lo que permite, precisamente por este motivo, sostener la existencia de una "genealogia» de la discursividad de los saberes científico-técnicos, en virtud de su consideración como prácticas socio-históricas.

La cuestión de la historicidad de los saberes nos tetrotrae a la "ciencia nueva" de Gian Battista Vico' — prolegómeno del historicismo e idealismo de Hegel - al indicar que hay una producción humana del "mundo histórico", y que es justamente en la historia donde puede hallarse la verdad de la ciencia,

1. Severino, E. 1986, pp.107 y ss. 
puesto que ahí coinciden verdad y certeza. Pero, verdad que aparece como representación, o sea, fenómeno producido por el hombre. Para este pensamiento moderno, conocimiento es producción en la medida en que es representación, y conocer es poseer el origen. La verdad de una hipótesis se hace visible con determinado acontecimiento producido por el aparato experimental (forma idealizada de la realidad). Aunque, para que ello ocurra, la hipótesis tiene que ser verdadera. Se da, en consecuencia, en Vico, un reconocimiento de la naturaleza social e histórica del saber; pero sobre la base de la racionalidad representacionista.

Con todo, las reglas que articulan las producciones discursivas y los enunciados no emanan fundamental ni únicamente del lenguaje y del habla. La composición de los enunciados no tiene como límite ni la lengua ni el sentido. Es preciso, por tanto, concebir los enunciados como ingredientes de formaciones discursivas en las que se distinguen: "objetos", "tipos de enunciación", "conceptos" y "elecciones temáticas" que en su dispersión sistemática permieten entrever una regularidad, cuyas "condiciones de distribución" responden a ciertas reglas de formación que son "condiciones de existencia»" Lo que conduce a un tratamiento de los discursos que desborda y, en cierto modo, rompe con la óptica lingüística.

La cuestión estriba, sobre todo, no en ver los enunciados y las formaciones discursivas como conjuntos de signos, de significantes que referencian a objetos, sino en ofrecer una descripción en tanto que práctica; como aquello que se sitúa más allá o tras la lengua.

\section{LOS UMBRALES DE LA DISCURSIVIDAD}

Es preciso subrayar, desde esta óptica genéricamente postpositivista, de que modo no toda formación discursiva puede ser catalogada de científica. Tan sólo puede ser calificada como tal, aquella cuyas proposiciones cumplen determinadas reglas de construcción. Sobre este particular, Foucault ha destacado varias modalidades de "emergencia" de la discursividad ${ }^{3}$ :

a) "Umbral de positividad" o momento en que una prácrica discursiva se individua y logra autonomizarse, actuando en un solo sistema de formación de enunciados.

b) "Umbral de epistemologización" o momento en que en la formación discursiva se "recortan" una serie de enunciados, que pretenden desem-

2. Foucault, M. 1979, pp. 62 yss.

3. Ibid, pp. 308. 
peñar en el saber un papel dominante, mediante la introducción de normas de "verificación" y "coherencia".

c) "Umbral de cientificidad". Se afirma que la epistemología así conformada ha traspasado ese umbral, cuando cumple ciertos "criterios formales" y obedece a determinadas "reglas de construcción".

d) "Umbral de formalización". Cuando la discursividad científica es capaz de definir los axiomas requeridos, los elementos empleados, las estrucruras y transformaciones consideradas válidas y, por tanto, legítimas, entonces puede affrmarse que tal discurso ha traspasado el umbral de formalización.

Este proceso se constituye mediante sucesiones, secuencias, desfases e implicaciones. Según un desarrollo cronológico examinado con detenimiento desde la perspectiva "arqueológica». Poniendo de relieve ciertas peculiaridades de suma importancia, detectadas en las producciones discursivas y que tienen como objeto o, mejor dicho, como "blanco" de sus afanes exploratorios al ser humano. Foucaulr ha remarcado que, si a lo largo de milenios el hombre fue además de un ser viviente un ser capaz de mostrarse como político - ateniéndonos a los cánones aristotélicos - con la modernidad se interfiere y pone en "entredicho" la propia vida del hombre. Estos cambios tienen lugar mediante la implantación sobre las poblaciones, principalmente en occidente, de un complejo sistema de "biopoderes", basado en una serie amplísima de observaciones, mediciones, cálculos y técnicas de poder/saber, que hay que situar en lo que fueron los prolegómenos de una cientificidad que toma al ser humano como meta de sus ataques y aprehensiones.

Este conjunto de movimientos, auténtica metamorfosis, comporta la introducción de dispositivos y tecnologías de "normalización" en las formaciones sociales modernas, afectando no solamante a la esfera de los saberes y discursividades acerca del ser humano, sino también a los saberes referentes a la naruraleza en general, prefigurando un corte en la episteme clásica que alumbra el nacimiento del "paradigma galileo-newtoniano".

Lo que interesa retener de los párrafos precedentes es, justamente, la naturaleza discursiva de los saberes científico-técnicos, dependientes de ciertas pautas que conforman lo que Gergen conceptúa de retórica reguladora de estas producciones discursivas. Discursividades, además, cuya objetividad no reside en una presunta concordancia o con vínculo representacional con una realidad subyacente, que en ese juego de lenguaje expresa su auténtica naturaleza. Lo que muestran estas descripciones objetivistas no es, por tanto, la existencia de una realidad última finalmente esclarecida, o de un enigma descifrado, puesto que ello supondría considerar a la realidad en términos "sustancialistas". Podemos hablar, a lo sumo, del establecimiento de una correspondencia entre descripciones o enunciados y determinadas normas retóricas. 
Enunciados o descripciones que obtienen su legitimidad al ser formulados como "regímenes de verdad", entendiendo por tales: "un conjunto de procedimientos ordenados para la producción, regulación, distribución y circulación de aserciones (...). La verdad está, así, vinculada por una relación circular a sistemas de poder que la producen y mantienen, y a efectos de poder que ella induce y reorienta hacia el mantenimiento de sí misma”.

\section{LAS DIMENSIONES SIMBOLICA EIMAGINARIA}

Llegados a este punto, conviene puntualizar que, inclinarse por la no reductibilidad de la actividad discursiva a la metáfora lingüística, no implica dejar de reconocer la existencia de lo simbólico e imaginario. Aspectos estos que, por regla general, han sido escamoteados o examinados de modo poco satisfactorio por la analítica foucaultiana.

La vertiente simbólica constituye una parte ineludible y fundamental de lo social; de las prácticas e interacciones desplegadas. Inseparable del sistema de poder y de los procesos de producción de subjetividad e intersubjetividad. C. Castoriadis lo expresa con claridad con estas palabras: "Todo lo que se presenta a nosotros, en el mundo social-histórico, está indisolublemente tejido por lo simbólico. No es que se agote en ello. Los actos reales, individuales o colectivos - el trabajo, el consumo, la guerra, el amor, el parto- los innumerables productos materiales, sin los cuales ninguna sociedad podría vivir un instante, no son (ni siempre, ni directamente) símbolos. Pero unos y otros son imposibles fuera de una red simbólica" ${ }^{5}$. Además, esto no ocurre tan sólo en el lenguaje, ocurre también en las instituciones que, a pesar de no constituir únicamente entidades simbólicas, sin esta dimensión no podrían existir. Resultarían ininteligibles, crípticas. Puede considerarse, en definitiva, que todo aquello que de un modo u otro forma parte y configura lo social es simbolizado: derecho, organización, economía, parentesco, sistema polftico, religión, etc.

Los símbolos, por otra parte, no permanecen aislados, están conectados con significados. Con arreglo a la esquemática descripción de Saussure (1977), el signo resulta de la combinación de significado y significante formando un todo. Sin embargo, el vínculo entre ambos es arbitrario, en el sentido de que no supone la realización de esencia alguna. No refleja ningún lazo natural. Es inmotivado. Por el contrario, el símbolo nunca es totalmente arbitrario. Entre significado y significante existe siempre algún tipo de nexo "rudimentario".

4. Foucault, M. 1978, pp. 14.

5. Castoriadis, C. 1983, pp. 201. 
Por su parte, L. Hjemslev (1984) efectúa una clasificación más precisa, basada en la diferenciación entre varias instancias: materia de la expresión (engloba al conjunto amorfo de los sonidos); materia del contenido (conjunto continuo y amorfo de los sentidos); forma de la expresión (abarca la trama relacional que configura las unidades fónicas); forma del contenido (trama relacional que configura unidades semánticas); sustancia de la expresión (clasificación que la forma fija en la materia fónica); sustancia del contenido (clasificación que la forma establece en la materia semántica).

Queda aún por mencionar otro factor, dentro de lo que podemos categorizar como "orden simbólico", y es el componente «imaginario" que actúa sobredeterminando las articulaciones de las redes simbólicas en cada periodo histórico, al prefigurar un «significado-significante» central que discrimina entre lo que se considera indiscutible y que se da por sentado - - actuando como sustrato de presuposiciones- y el resto de las cosas. Posibilitando el discernir entre aquello que se juzga importante y lo que no; «origen del exceso de ser de los objetos de inversión" individuales o colectivos, y que aparece conceptuado como "imaginario social" de un periodo histórico determinado. G. Spencer Brown (1972) se ha referido a lo imaginario como tercer valor frente a los valores de lo verdadero (o positivo) y lo no verdadero (o negativo).

Es así como se entrelazan los procesos de simbolización y el imaginario, en el espacio que delimita el "orden simbólico dominante». En este sentido, lo simbólico y el imaginario serían componentes inseparables de las relaciones sociales, y por ende de las relaciones de poder y saber. Su omisión hace ininteligible procesos y dispositivos básicos para la gobernabilidad de lo social en general y, en particular, de las líneas de fuga o de las tangencialidades discordantes.

\section{LA PARADOJA DE LA AUTORREFERENCIA}

La actividad científica y técnica en este ámbito posee una especificidad propia. Se trata básicamente de una práctica autorreflexiva (y depredadora). La subjetividad, aquello que proviene del sujeto, se expande por todo el espacio de la investigación. No hay posibilidad de distanciamiento, de separación respecto al objeto, puesto que es el propio sujeto como ser social lo que se examina. Indagación en la que, parádojicamente, el examinador es a su vez lo examinado. Estamos ante un círculo vicioso en esta singular polaridad en que el sujeto investigador aspira a obtener fragmentos de verdad del objeto de estudio, que resulta ser de alguna manera el mismo. La observación bascula, para Lupasco (1972), entre elementos enfrentados, antagónicos: por un lado, un sujeto que aparece como conjunto actualizado de acontecimientos; por 
otro, un objeto, campo de acontccimientos posibles o en potencia. El científico social topa con algo que habla, y esto es algo que no ocurre en las ciencias de la naturaleza. El sustrato ontológico y la naturaleza de ambos (investigador e investigado) son los mismos, aunque ocupan lugares distintos en la estructura asimétrica de los dispositivos científicos. De ahí el carácter autorreferencial de este tipo de indagaciones.

El círculo vicioso de la autorreferencia se ha intentado solventar de varias maneras ${ }^{6}$. Lévi-Strauss (1973) lo resuelve al circunscribir la investigación únicamente a las ciencias sociales. Desde las ciencias humanas se ha querido romper este círculo al recurrir a los procedimientos de las ciencias naturales, o excluyendo la dimensión hablanfe del objeto.

B. Russell y A.N. Whitehead (1910) crean la "teoría delos tipos lógicos" para salvar esta circularidad, formando una jerarquía de lenguajes que poseen distintos niveles de potencia lógica: lenguaje del objeto, metalenguaje, etc... $O$, de otro modo, el que habla el habla (objeto, que utiliza el lenguaje objeto); el que habla (analiza, examina, prescribe,...) del habla que utiliza el objeto (sujeto, utiliza un metalenguaje). A. Wilden (1979), desde una posición netamente diferenciada, propugna trastocar el sistema de clausura establecido por la lógica tradicional, basada en leyes de identidad y no contradicción, desde una lógica situada a un nivel superior.

Sin embargo, las perspectivas "arqueologican y"genealógica" invitan a ver las cosas de otro modo, al destacar como las ciencias sociales (y humanas) se inscriben en estrategias y tácticas que vienen desarrollándose desde el siglo XVIII. De ahí se desprende la necesidad de promover una analítica y una episteme que dirija su atención hacia los elementos que conforman, a modo de fuerzas (soporte objetivo y objetivizante), particularcs tecnologías "disciplinarias" y de "nomalización", que subsumen y determinan el lenguaje. Tales consideraciones suponen una mutación en el punto de vista del análisis de la realidad social, al revelar que - tras la aparente inocuidad de los "hechos" $o$ de los sense data, y formando parte de su propia configuración- lo que se vislumbra es una compleja trama de antagonismos y oposiciones.

Desde esta óptica, Descartes y Hobbes pueden ser considerados los precursores de la aplicación de los medios experimentales y matemáticos de las ciencias físicas al estudio del comportamiento, tal y como aparecen en Galileo y Newton. Peters y Tajfel han remarcado que el autor de Leviatan: "fue el primero en intentar una explicación sistemática de todas las acciones humanas, en los mismos términos que fueron utilizados para explicar el comportamiento de los cuerpos inanimados" 7 .

6. Ibáñez, J. 1985 , pp. 53 y ss.

7. Gross, G. 1983, p. 46. 
En la vertiente tecnológica, o de la ciencia aplicada, destacan, actualmente, los elementos objetivos estereotipados en el bardware, así como la potenciación de lo inmaterial plasmado de forma reductiva en el software informacional, cuyo ejemplo in extremis viene representado, según P. Virilio (1984), por el inmaterial bélico y por el sofisticado diseño de la Doomsday Machine Ilustrando, en este caso, el papel sobredeterminante de la guerra y de su discursividad. Hegel aludió en la Fenomenología del Espiritu a la guterra como el modelo de comunicación en el cual emisor y receptor no pueden hablar al mismo tiempo. Uno de los contendientes debe permanecer en silencio o, lo que es lo mismo, ser vencido. En la relación establecida entre ambos, cada uno tiende "a la muerte del otron. Más en concreto, y aplicando estas consideraciones al dominio de la ciencia, se dirá que: «el conocimiento científico es una guerra con(tra) su objeto, y con(tra) los sujetos que hay en él ${ }^{8}$.

\section{LO IDEOLOGICO Y LO CIENTIFICO EN LA PRODUCCION DE REGIMENES DE VERDAD}

De acuerdo con cierta interpretación, las ciencias sociales deben ser categorizadas como formaciones ideológicas más que como formaciones cientifi-. cas. Suministran una visión deformada de lo real. Están ubicadas entre la representación y la presencia. Se aduce, al respecto, que en este ámbito no ha llegado a consumarse la ruptura con la ideología. No obstante, suponiendo que esto fuera así y teniendo en cuenta lo apuntado con argumentos diversos por L. Mumford $(1967,1982)$ y P. K. Feyerabend (1981), es posible sostener que esta ruptura tampoco ha tenido lugar, de un modo total e irreversible, en las ciencias físicas y de la naturaleza. La persistencia de elementos ideológicos (preconcepciones, componentes míticos, etc.) como algo inherente a la propia racionalidad científica y a su inserción en específicas estructuras político-económicas y culturales, permiten corroborar esta postura. Lo cual, a su vez, desautoriza la ficción bachelardiana (Bachelard, 1971, 1973) consistente en imaginar la existencia de una parcela autónoma, resultante final de un largo y complejo proceso de destilación fraccionada para eliminar las impurezas y adherencias representadas por el ulastre ideológico». Todo ello hace posible precisar de un modo más adecuado el estatuto epistemológico de las ciencias sociales.

Si partimos de una noción de verdad como lo que ha sido aceptado durante largo tiempo, como la adecuación entre el enunciado y lo que se considera la realidad. Y, si a su vez, lo que pretendemos es algo más concreto, a sa-

8. Ibàñez, J. op. cir. p. 56. 
"Papers": Revista de Sociologia

ber, la articulación científica y la producción de efectos de verdad como consecuencia de ello, entonces es necesario que se establezca una vinculación entre: el "rigor analítico y formal de los conceptos operatorios" y "el rigor analítico y real de los conceptos a los que se ha llamado sistémicos" ".

En el terreno de las ciencias sociales, señala J. lbánez, las técnicas de investigación empírica se especializan en conceptos operatorios, y las teorías en conceptos sistémicos, para la elaboración de modelos. No obstante, toda esta discursividad pierde su encanto si recurrimos de nuevo al «Teorema de Gödel", demostrativo de que no existe ningún metalenguaje universal que sirva para probar el lenguaje científico. Además, en otro orden de cosas, como es sabido, de las "relaciones de incertidumbre" de Heisenberg se desprende que ningún instrumento u operador puede poner a prueba un hecho, debido a que el propio proceso observacional y de recolección de datos introduce distorsiones. Respecto a la posibilidad de probar los "hechos" de forma definitiva, resulta ilusorio imaginar la existencia de un "probador absoluto"; auténtico deus ex-macbina. Lo único que cabe son, por consiguiente, meras aproximaciones a algo que en todo momento constituye una producción o un constructo.

Así, a pesar de que esta situación concierne a las ciencias naturales y físicas, las dificultades se agudizan notablemente, adquiriendo un talante propio, en el caso de las ciencias sociales, tanto en la vertiente teorética como en la empírica ya que, si nos guiamos por cierta ortodoxia cientifista, comportan la imposibilidad de falsar teorías y establecer hechos a partir de teorías.

Las teorías consrituyen prácricas sociales que, de acuerdo con la clasificación de T. Herbert (1966), podemos subdividir en: a) prácticas empíricas (incluyen prácticas récnicas y prácticas políticas); b) prácticas especulativas (incluyen prácticas ideológicas y prácticas teóricas). Entre las prácticas especulativas y las empíricas se dan procesos de retroalimentación. Los discursos teóricos de las ciencias naturales retroalimentan las prácticas técnicas. Los discursos teóricos de las ciencias sociales determinan las prácticas políticas y las relaciones sociales. Las prácticas ideológicas inciden en todos los niveles, no sólo en lo epistémico sino rambién en el despliegue práctico y discursivo. Tanto el científico social como el físico o el astrofísico, por poner algunos ejemplos, participan de ese influjo de muchas maneras (cosmologias, figuras y pautas del sistema consensual, valores,...).

La elaboración de producciones ideológicas, de enunciados y de discursividades formulados como verdaderos, constituye uno de los requisitos fundamentales de todo sistema de ordenación socio-político basado en la domina-

9. Bordieu, P. 1976, pp. 54 y ss. 
ción (piramidal, asimétrico,...). Segregando representaciones que funcionan como matrices interpretativas. Marcos hermenéuticos para las interacciones según las reglas del juego estipuladas. Para N. Luhmann (1969), en las sociedades postindustriales en que la ideología funciona según el modelo cibernético, la normarividad de las leyes es reemplazada por la performatividad de los procedimientos. La posibilidad de que cierta orden sea considerada justa, aumenta con la probabilidad de ser ejecutada, y ésta a su vez se incrementa con la performatividad de quien la prescribe. Lo cual, a parte de evocar lejanamente el escepticismo de Montaigne, remite a la performatividad de los elementos que forman la trama de poder.

Asimismo, el control ideológico, sostiene J. Ibáñez, "disfraza" las prescripciones que son impuestas de descripciones que poseen la apariencia de algo coherente. Objetos y sujetos, vistos así, parecen "naturales" y no uproducidos", participando de la creencia generalizada en el carácter no mediato y transparente de las relaciones. De este modo, lo que conceptuamos como ciencias sociales, "construyen" sus discursos "teóricos" en continuidad con la especulación discursiva o institucional ideológica, sin operar la ruptura que manifiesta la imposición y la ocultación o disimulación de esa imposición. Su referente no es la realidad, sino la representación ideológica de la realidad (con mapas disfrazados de copias o calcos): pero utiliza dispositivos de constatación o captura empírica que anclan en la realidad y fundan y justifican ese anclaje en los discursos "teóricos", y que retrodeterminan, por caminos distorsionados, las prácticas empíricas, técricas y políricas...." 10 .

Por último, puede apreciarse que, en la medida en que el sistema de poder recurre para legitimarse a performances o actuaciones, la función de lo ideológico y por tanto de las ciencias sociales, desde el punto de vista de su consideración como generadores de ideología, decrece o deja de tener interés para el sistema. A no ser como dispositivos para propiciar la descodificación/recodificación, y como artefactos tecnológicos para corregir y regular los comportamientos y las formas de agregación social; las distorsiones y pérdidas originadas al aplicar los esquemas inputloutput. $\mathrm{O}$, con otras palabras, por su contribución a la implantación de las diversas modalidades de informatización de lo social, en la inútil búsqueda del poder omnímodo sobre ese magma de comportamientos y prácticas, etiquetado por el reduccionismo de la uteoría de sistemas" de "sistema abierto". Búsqueda paradójica, pues, del aumento de neguentropiá, que remite a la fábula borgiana de aquel monarca que para cartografiar su reino tuvo que contar con la colaboración de todos los súbditos, y el resultado fue la ruina económica del país.

10. Ibáñez, J. op. cir. p. 124. 


\section{PROVISIONALIDAD E INCERTIDUMBRE}

Para finalizar, es posible constatar que los saberes y las prácticas de que se nutren las ciencias sociales aparecen presididos por el signo de la provisionalidad y temporalidad (pluralidad de tiempos). Sometidos a la ineluctable necesidad de revisar permanentemente las conclusiones establecidas y los hallazgos, debido a la naturaleza cambiante y esrocástica de los comporramientos y de las relaciones sociales. Así, el carácter recurrente (los saberes y artefactos derivados de las prácticas precedentes reviercen sobre la propia realidad), sociohistórico (los saberes y artefactos se generan y están condicionados por la historicidad de lo social) y con una insoslayable dimensión política (lo político inviste lo social y constituye un producto del despliegue de la "forma Estado") y formalizadora, evidencian ciertos rasgos de los saberes y dispositivos en este ámbito que los diferencian de las ciencias físicas y de la naturaleza, otorgándoles un sesgo específico. Se trata, en efecto, de determinados rasgos epistémicos, ontológicos y prácticos que se desprenden de la singularidad del ser social, afectando de un modo particular a las producciones discursivas que le conciernen.

Esta situación obliga, por otra parte, a una permanente labor desconstructiva ${ }^{11}$ para contrarrestar la esclerosis de estos saberes diseñados, en un principio, para funcionalizar la extrema complejidad del magma social. Este desfase y/o discontinuidad en relación con el desarrollo de los acontecimientos, unido al carácter en parte imprevisible de lo social, provoca, además, un desgaste prematuro del ya de por sí limitado alcance de las producciones teóricas.

Carecer de un discurso o gran relato prevalente que actúe en calidad de marco teórico general tiene efectos paradójicos. Por un lado propicia la dispersión temática, de los conceptos y procedimientos, dotando a la práctica investigadora en este terreno de cierta vulnerabilidad. En cambio, como contrapartida, esta situación tiene la gran ventaja de que permite abrir todo un abanico de posibilidades innovadoras, en un sentido profundamente crítico y desconstructivo. Jugando, al propio tiempo, con el carácret "intensional» 12 del pensamiento, que supone que las descripciones o aseveraciones pueden "flotar" sin estar necesariamente adheridas a objeto conocido alguno. Esta flexibilidad permite imaginar cosas inexistentes, hipótesis y amalgamas de piezas a priori separadas, para comprobar el efecto que ello produce. En cierto modo, si nos atenemos al lenguaje informacional, es lo que diferencia al software del pensamiento del hardware neuronal.

Por último, como ha señalado K. Gergen, ello permite descargar la retórica acerca de la realidad social del lastre de las ilocuciones objetivistas, favoreciendo

11. Ibáfiez, T. 1989, pp. 109-133.

12. Hofstadtet, D.R. 1979, pp. 337 y ss. 
así el enriquecimiento de las indagaciones; inclusive aunque éstas se presenten al margen o contra el método. Recogiendo una aspiración perfectamente reflejada en este interesante fragmento de Hegel, citado por Feyerabend, que dice así: "Cuanto más sólido, bien definido y espléndido es el edificio erigido por el entendimiento, más imperioso es el deseo de la vida (...) por escapar de él hacia la tibertad. (Al mostrarse como) la razón, este edificio es negativo y dialéctico, porque reduce a la nada las detalladas determinaciones del entendimiento ${ }^{13}$.

\section{BIBLIOGRAFIA}

Alexander, J. C. et al. (1990), La teoria social hoy, Madrid, Alianza Universidad. Bachelard, G. (1971), La formación del espiritu cientifico, México, Siglo XXI.

Bacherlard, G. (1973), Epistemologia, Barcelona, Anagrama.

Baudrillard, J. (1984), Las estrategias fatales, Barcelona, Anagrama.

Baudrillard, J. (1991), La guerra del Golfo no ha tenido lugar, Barcelona, Anagrama.

Bordieu, P. et al. (1976), El oficio del sociólogo, Madrid, Siglo XXI.

Castoriadis, C. (1983), La institucion imaginaria de la sociedad, Barcelona, Tusquets.

Castoriadis, C. (1978), Les carrefours du labyrinthe, París, Seuil.

Chalmers, A. F. (1986), ¿Qué es esa cosa llamada ciencia?, Madrid, Siglo XXI.

Deleuze, G. (1968) Différence et répétition, Paris, PUF,

Deleuze, G., Guattari F. (1980), Mille Plateaux, Paris, Minuit.

Derrida, J. (1971), De la gramatalogía, México, Siglo XXI.

Derrida, I. (1989), La desconstrucción en las fronteras de la filosofia, Barcelona, Paidós.

Feyerabend, P. K. (1981), Contra el método, Barcelona, Ariel.

Feyerabend, P. K. (1981), Tratado contra el método, Madrid, Tecnos.

Feyerabend, P. K. (1989), Limites de la ciencia, Barcelona, Paidós.

Foucault, M. (1978), "The political function of intellectual", en Radical Philosophy, n. $[7$, p. 14.

Foucault, M. (1978), Microfisica del poder, Madrid, La Piqueta.

Foucault, M. (1979), La arqueologia del saber, Madrid, Siglo XXI.

Giddens, A. (1987), Las nuevas reglas del método sociológico, Buenos Aires, Amorrortu. Giddens, A., Turner, J. (1990), La teoría social hoy, Madrid, Alianza Universidad. Gouldner, A. (1979), La crisis de La sociologia occidentah Buenos Aires, Amorrortu.

Gross, G. (1983), "Selección artiftcial", en AA. VV. La reconstrucción de la psicologia social, Barcelona, Hora.

Hanson, N.R. (1985), Patrones de descubrimiento. Observacion y explicación, Madrid, Alianza Universidad.

\section{Feyerabend P.K. 1981, p. 14.}


"Papers": Revista de Sociologia

Hjemslev, L. (1984), Prolegómenos para una teoria del lenguaje, Madrid, Gredos. Hofstadter, D. R. (1979), Gödel, Escher, Bach: And Eternal Golden Braid, London, Penguin Books.

Ibáñez, J. (1979), Más allé de la sociologia, Madrid, Siglo XXI.

Ibánez, J. (1985), Del algoritmo al sujeto, Madrid, Siglo XXI.

Ibáñez, T. (1989), "La psicología social como dispositivo desconstruccionista», en $E l$ conocimiento de la realidad social, Barcelona, Sendai.

Kuhn, T.S. (1971), La estructura de las revoluciones cientiffcas, Madrid, FCE.

Kuhn, T.S. (1978), Segundos pensamientos sobre paradigmas, Madrid, Tecnos.

Kuhn, T.S. (1989), ¿Qué son las revolucionescientificas?, Barcelona, Paidós.

Lévi-Strauss, C. (1973), Anthropologie Structurale, Paris, Plon.

Luhmann, N. (1969), Legitimation Durch Verfahren, Neuwied.

Luhmann, N. (1985), Come è possibile l'ordine sociale, Roma-Bari, Laterza.

Luhmann, N. (1979), Potere e complessità sociale, Milano, II Saggiatore.

Luhmann, N. (1990), Sociedad y sistema: La ambición de la teoría, Barcelona, Paidós.

Lupasco, S. (1972), "La logique de l'évenement", en Communications, n. 18.

Lyotard, F.P. (1979), La condition postmoderne, París, Minuit.

Mumford, L. (1967), The myth of machine, Harcourt, Brace and World.

Mumford, L. (1982), Técnica y civilización, Madrid, Alianza Universidad.

Parsons, T. (1951), The social system, New Yotk, Free Press.

Russell, B., Whitehead, N. W. (1910), Principia Mathematica, Cambridge, Cambridge Universiry Press.

Saussure, F. (1977), Curso de lingǘstica general, Buenos Aires, Losada.

Severino, E. (1986), La filosofia moderna, Barcelona, Ariel.

Spencer Brown, G. S. (1972), Laws of Form, New York, Bantam Books.

Toulmin, S. (1970), Physical Reality, New York, Harper and Row.

Virilio, P. (1977), Vitesse et politique, París, Galilée.

Virilio, P., Lotringer S. (1983), Pur War, New York, Columbia Universiry.

Virilio, P. (1984), "L'état nucléaire", en Change Internatinal, n. 2, París

Wilden, A. (1979), Sistema y estructura, Madrid, Alianza. 